\title{
Can an automated early warning system derived from continuous physiologic monitoring prevent disaster?
}

\author{
Steven M. Schwartz, MD, MS, FRCPC, FAHA
}

\footnotetext{
From the Divisions of Cardiac Critical Care Medicine and Cardiology, Departments of Paediatrics and Critical Care Medicine, The Hospital for Sick Children and The University of Toronto, Toronto, Ontario, Canada. Disclosures: Author has nothing to disclose with regard to commercial support.

Received for publication April 3, 2016; accepted for publication April 4, 2016; available ahead of print May 6, 2016.

Address for reprints: Steven M. Schwartz, MD, MS, FRCPC, FAHA, Department of Critical Care Medicine, The Hospital for Sick Children, 555 University Ave, Toronto, ON M5G 1X8, Canada (E-mail: steven.schwartz@ sickkids.ca).

J Thorac Cardiovasc Surg 2016;152:3-4

$0022-5223 / \$ 36.00$

Copyright (c) 2016 by The American Association for Thoracic Surgery

http://dx.doi.org/10.1016/j.jtcvs.2016.04.014
}

Critical care physicians use multiple sources to assess individual patient risk for deterioration and adverse events. Pediatric cardiac patients present especially complex cases because cardiovascular physiology and circulatory patterns vary, making factors such as oxygen saturation or even blood pressure context dependent. Estimates of course vary from clinician to clinician, with factors such as experience, fatigue and the overall acuity of the critical care unit influencing the ability to predict risk and intervene to avoid adverse events. Consequently, risk assessments derived from continuously acquired physiologic data that can be updated and displayed in real time have major potential value.

In this issue of The Journal of Thoracic and Cardiovascular Surgery, Rusin and colleagues ${ }^{1}$ report a promising start to this approach for neonates and infants with single-ventricle physiology (in-parallel systemic and pulmonary circulation). They compared direct and derived variables acquired between 1 and 2 hours before events, defined as either unplanned intubation or cardiopulmonary resuscitation, with data from periods of greater stability.

The high rate of adverse events during the interstage period for patients with single-ventricle physiology make them an excellent population in which to develop this methodology. ${ }^{2}$ This work could be expanded to other types of congenital heart disease, because individual risk is predominantly based on comparison with the patient's own baseline, although the specific variables with greatest impact could differ. It also makes use of the relatively new ability to acquire and rapidly analyze complex data to derive variables that would not be readily evident to even experienced clinicians, such as the 3-dimensional variability of the ST-segment vector.

The success of this approach is exciting, but there remain important limitations to its broad applicability. Cardiopulmonary resuscitation could always be considered a failure of early risk assessment; in contrast, unplanned intubation may be an appropriate intervention to prevent events of greater severity. In terms of the acute event, the goal with intubation is to control the timing and circumstances, not

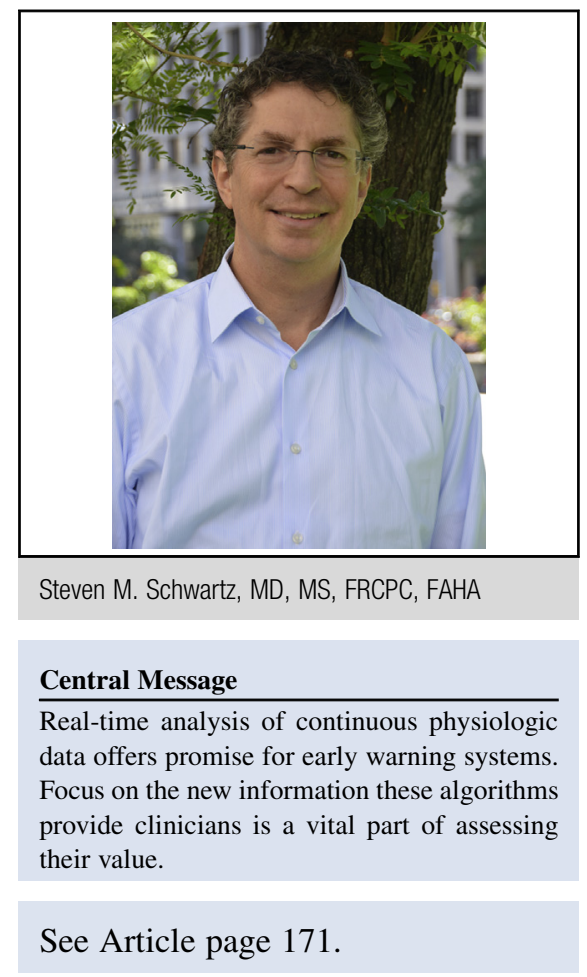

necessarily to prevent it entirely. Without the clinical details of what occurred at the bedside at the time this index was generated, it is hard to know how consistently this risk assessment provides actionable information. Furthermore, these patients may not be at standard risk in the overall context of single-ventricle physiology. The events used to develop this index occurred a mean of 48 days after surgery, whereas the average stay after the Norwood operation in the Single Ventricle Reconstruction trial was 24 days. ${ }^{3}$ Cardiopulmonary resuscitation events and critically low oxygen delivery also occur early after surgery when the patient is intubated, a time frame that was not evaluated in this study. Although this is an acceptable approach for model development, it imposes important limitations to generalization.

This report may be the first to use real-time analytics to estimate risk from continuous physiologic monitoring, but it definitely will not be the last. Incorporation of data from more sources and careful comparison with data integration by clinicians will continue to maximize the value of these systems.

\section{References}

1. Rusin CG, Acosta SI, Shekerdemian LS, Vu EL, Bavare AC, Myers RB, et al. Prediction of imminent, severe deterioration of children with parallel circulations using real-time processing of physiologic data. J Thorac Cardiovasc Surg. 2016; $152: 171-7$. 
2. Ghanayem NS, Allen KR, Tabbutt S, Atz AM, Clabby ML, Cooper DS, et al; Pediatric Heart Network Investigators. Interstage mortality after the Norwood procedure: results of the multicenter Single Ventricle Reconstruction trial. J Thorac Cardiovasc Surg. 2012;144:896-906.
3. Ohye RG, Sleeper LA, Mahony L, Newburger JW, Pearson GD, Lu M, et al; Pediatric Heart Network Investigators. Comparison of shunt types in the Norwood procedure for single-ventricle lesions. N Engl J Med. 2010;362: 1980-92. 